\title{
Cirandar: São Gabriel-RS entra na roda de narrativas sobre docência
}

\author{
Cirandar: São Gabriel-RS joins the wheel of \\ narratives about teaching
}

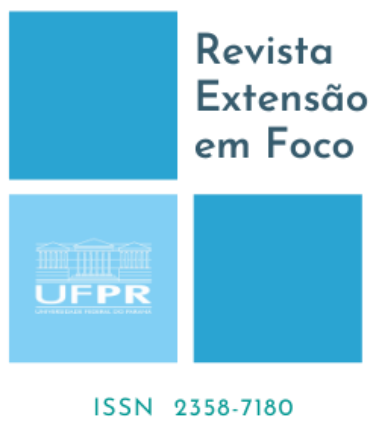

\author{
Loraine Rodrigues Jardim ${ }^{1}$
}

\begin{abstract}
RESUMO
O Cirandar iniciou-se em São Gabriel-RS através de uma busca incessante por oportunidades de aprender e de dar voz às nossas experiências vivenciadas em sala de aula. Este relato tem como objetivo compartilhar um pouco dessa trajetória, da chegada das rodas de conversa sobre docência nessa cidade, dando início a um processo de investigação na escola. Nossa roda de São Gabriel é composta por professores da rede básica, desde a educação infantil até o ensino médio, com a participação também de gestores e de acadêmicos que exercem monitoria nas escolas. No movimento de ciranda, unidos, de mãos dadas por um objetivo comum, encontramos espaço de fala, de escuta e de acolhida às angustias do cotidiano da docência. Precisamos de espaços como esse para compartilhar as experiências de sala de aula e dar voz àqueles que fazem a educação básica. Que mais cidades e professores possam ser acolhidos pela metodologia do Cirandar e tenham suas trajetórias docentes escutadas e valorizadas.
\end{abstract}

Palavras-chave: Formação continuada. Educação básica. Cotidiano escolar.

\section{ABSTRACT}

Cirandar started in São Gabriel-RS through an incessant search for opportunities to learn and give voice to our experiences in the classroom. This report aims to share a little of this trajectory, the arrival of the conversation circles about teaching in this city, initiating an investigation process in the school. Our São Gabriel circle is made up of teachers from the basic network, from early childhood education to high school, with the participation also of managers and academics who exercise monitoring in schools. In the ciranda movement, united, hand in hand for a common goal, we find space for speech and listening, for welcoming the anxieties of everyday teaching. We need spaces like this to share classroom experiences and give a voice to those who do basic education. That more cities and teachers can be welcomed by the Cirandar methodology and have their teaching trajectories listened to and valued.

Keywords: Continuing education. Basic education. Everyday school.

\section{INTRODUÇÃO}

O Cirandar - rodas de investigação na escola, se faz presente na minha trajetória profissional a alguns anos. A origem da minha participação em rodas de conversa sobre

\footnotetext{
${ }^{1}$ Mestra em Ciências pela Universidade Federal de Pelotas, professora de Ciências da Secretaria Municipal de Educação de São Gabriel, São Gabriel, RS, Brasil. Email:lorodrigues2@gmail.com ORCID: https://orcid.org/0000-0002-4224-8202
} 
a escola se fez, na verdade, desde os tempos de minha formação inicial, como bolsista PIBID em seu primeiro ano de existência, participando do evento Investigação na Escola.

Posterior a esse período, já na atividade de docência após minha graduação inicial, deparei-me com a realidade dos professores de rede básica de cidade do interior: participar de formações se torna muito difícil em relação a gastos, tempo de deslocamento, envolvendo também dispensas das escolas que por vezes não compreendem nossa constante busca por discutir a prática docente.

Caro colega, você deve estar se perguntado porque relato isso logo no início do texto. Relato porque foi dessa dificuldade vivenciada que nasceu a roda Cirandar na cidade de São Gabriel-RS, não sendo vinculada a grupo de estudo aqui pré-existente, mas de um desejo comum de ter um espaço de escuta sobre nossa sala de aula. Este relato tem como objetivo compartilhar um pouco dessa trajetória, da chegada das rodas de conversa sobre docência nessa cidade, dando início a um processo de investigação na escola.

\section{O CIRANDAR EM SÃO GABRIEL}

São Gabriel fica na mesorregião sudoeste do estado do Rio Grande do Sul, distante $328 \mathrm{~km}$ da capital Porto Alegre e aproximadamente a mesma distância de Rio Grande, cidade de origem do Cirandar. No contexto dos 497 municípios do estado do Rio Grande do Sul é o $37^{\circ}$ maior em população (62147 habitantes - estimativa IBGE(2020). Ver figura 1.

Figura 1 - Localização de São Gabriel-RS

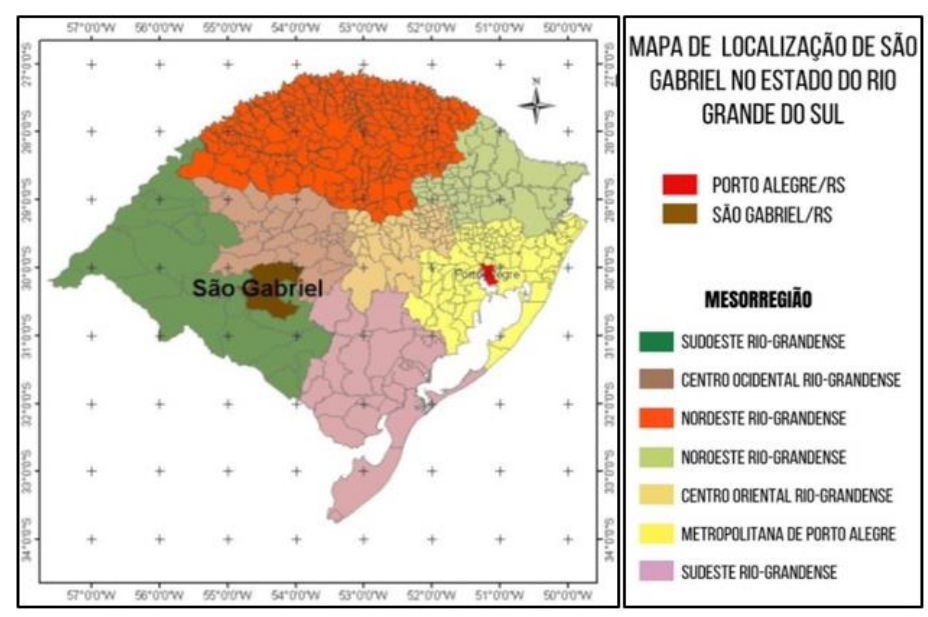

Fonte: Pastorio (2015,p.16). 
As oportunidades de formação continuada em São Gabriel encontram-se em sua maioria disponibilizadas pelas mantenedoras de ensino, com poucas opções de cursos de formação docente relacionadas com as universidades públicas, que tem aos poucos ocupado esse espaço carente da nossa região.

No ano de 2018, em busca de oportunidades de manter contato com as universidades para a realização de formações, me deparei com a divulgação de que o Cirandar teria uma roda inicial em São Gabriel, vinculada ao grupo de estudos do mestrado da UNIPAMPA de Bagé. Encontrei ali a oportunidade de participar pela primeira vez desse processo de formação ao qual acompanhava de longe ocorrendo nas escolas de Rio Grande.

Nessa proposta inicial, realizamos uma roda coordenada por uma colega da rede municipal e daríamos sequencia junto ao grande grupo em Rio Grande. Destaco que o Cirandar chega em minha vida nesse processo de busca, na sensação inquietante de que não poderia me deixar abater por alguns percalços que encontramos nas nossas trajetórias docentes, era um momento de retomada de alguns objetivos.

Abreviando esse início do relato para logo discorrer sobre o que eu realmente gostaria, apenas duas gabrielenses, eu e a organizadora da roda, conseguimos nos deslocar por conta própria até Rio Grande para o encontro final em março de 2019.

Quando retornava de Rio Grande, dirigindo sozinha pela BR290, sentindo-me renovada com a vivência daquele encontro maravilhoso, desejei que meus colegas professores também pudessem participar de momentos como aquele, mas nossas demandas reais, de deixar família, viajar, investir, conseguir dispensa na escola (o sábado era letivo) envolve um investimento de tempo e valores financeiros que não é acessível a todos nós da rede básica, torna-se fácil desistir de participar de formações.

Foi desse desejo de compartilhar aquela sensação boa de participar da roda Cirandar que busquei ampliar o Cirandar em São Gabriel. Com o incentivo da professora Maria do Carmo Galiazzi e da professora Aline Dorneles e também com o apoio que recebi da Secretaria Municipal de Educação de São Gabriel, em 2019 nossa roda passou das 5 pessoas iniciais para mais de 90 inscritos. Professores gabrielenses da rede pública estadual, municipal e também da rede privada, que partilhavam da mesma vontade de participar desse tipo de processo formativo. 
Em agosto de 2019, tivemos o prazer de receber a equipe organizadora do Cirandar na nossa cidade, para uma roda emocionante, onde tecemos uma rede de retalhos de assuntos, angustias, esperanças e experiências sobre educação. Ver figura 2.

Figura 2 - Roda Cirandar em São Gabriel-RS no ano de 2019

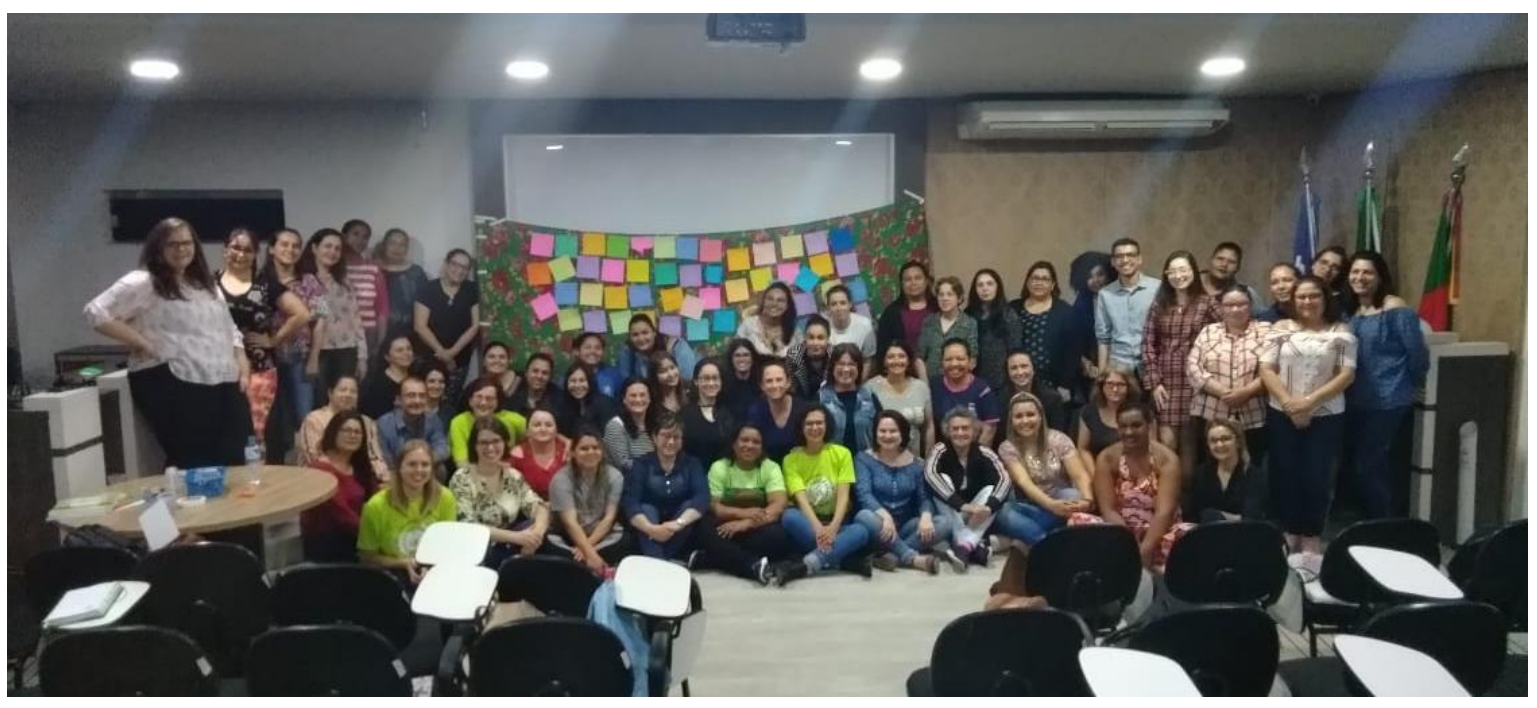

Fonte: arquivo pessoal

Que linda roda compomos aqui pela fronteira oeste, ultrapassando todas as dificuldades encontradas pelo desconhecimento do processo de autoformação e também pelo medo e dificuldade da escrita, tão abandonado pelos professores da rede básica. Ao nos afastarmos da escrita acadêmica, com suas formatações e peculiaridades, acabamos enfrentando a insegurança de escrever sobre nossas práticas. Em alguns cursos de Licenciatura essa escrita não é incentivada, silenciando ainda mais aos professores de Educação Básica.

Infelizmente a pandemia nos privou da oportunidade de participar do encontro final em Rio Grande, mas não diminuiu nossa vontade de partilhar. Sendo assim, foi uma grata surpresa receber o convite para ser uma das coordenadora do Cirandar 2020, em sua nova versão, adaptado ao contexto pandêmico, com um número reduzido de participantes mas com rodas espalhadas em diversas cidades. Em São Gabriel tivemos colegas que já eram cirandeiros do ano anterior, mas também agregamos alguns amigos queridos que partilhavam da vontade de participar. 


\section{OS ENCONTROS DA RODA EM SÃO GABRIEL}

Adaptados então ao formato online, formamos uma roda de 18 professores da rede municipal de ensino, atuantes desde a educação infantil até o ensino médio. Nossos encontros ocorreram mensalmente, após cada envio de carta da professora Maria do Carmo Galiazzi, orientando o processo formativo. Foram propostas a escrita da carta 1 de apresentação e partilha da nossa trajetória como docentes, carta 2 de compartilhar as adaptações ao período pandêmico e de apontar escolhas de temas de estudos e a carta 3 como uma retomada às cartas anteriores e aprofundamento do nosso assunto.

Não faço esse relato como coordenadora de roda, pois ali entre meus colegas, participei realmente em partilha, com a demanda da educação básica a ser relatada. As minhas cartas escritas ao longo do processo formativo foram sobre as experiências docente e angustias vivenciadas no período.

Nossas cartas foram disponibilizadas em pasta do google drive para apreciação de todos da roda, em especial a carta 1 de apresentação, em que realizamos uma leitura em pares interna, da nossa própria roda. Que riqueza de relatos, lindas trajetórias docentes, repletas de experiências que precisam ser faladas e principalmente escutadas. Colegas com quem convivemos no dia a dia nos corredores das escolas, na correria entre um planejamento e outro, entre as trocas de sala, e que por vezes não conhecemos sua trajetória, sua formação e principalmente as dificuldades encontradas em suas formações.

Descrevo aqui um tema muito discutido em nossas rodas, a necessidade de ter nossa sala de aula relatada, como também a grande necessidade de oportunidades como essa serem possibilitadas cada vez mais aos professores da rede básica. A escrita no gênero epistolar, em formato de carta, torna nossas experiências mais acolhidas. Como destaca Bettiol (2016, p.235) em seus estudos sobre o gênero epistolar, a "carta é dirigida a determinada pessoa, com quem se divide conhecimentos muito particulares". Dessa maneira, dividimos nossos relatos de experiências docentes com quem acreditamos que os estarão acolhendo, tornando-se uma alternativa para a falta de prática com os textos de formatação acadêmica que nos distanciam da escrita, por receio das avaliações. Um texto como esse, carente de citações e grandes lista de referências, não busca representar falta de conteúdo, e sim excesso de fontes de orientações. Na educação básica temos nos 
guiado por tudo que lemos, que ouvimos, que observamos e que vivenciamos. Ainda não existe como formatar tudo isso nas referências.

O gênero carta, a estrutura narrativa, com todo seu respaldo teórico de importância, acolhe ao professor de educação básica, que quer relatar suas vivências docentes. Nesse diálogo estabelecido, nas propostas de leituras em pares, nossos relatos são acolhidos, encontramos um leitor atento, vivenciamos a ansiedade pela resposta. " $\mathrm{O}$ gênero epistolar é o diálogo entre o emissor e o destinatário, um texto escrito a quatro mãos em que é imperativo responder à carta recebida" (BETTIOL, 2016, p.230).

Estamos cansados de formações obrigatórias em que nossas vozes não são ouvidas, do especialista determinando fazeres ao executor. Precisamos compartilhar e expor aos outros como é a educação básica e o quanto essa base precisa ser fortalecida.

Escutem esse grupo que está precisando ter acesso a boas formações continuadas, a boas rodas como a do Cirandar. Que precisam ser incentivados a superarem a necessidade de deslocamentos, investimentos e solicitações de dispensa para participarem de eventos. Precisam superar o medo de divulgar suas escritas. Vamos utilizar esse recurso online que se fez tão obrigatório nesse período de pandemia e aproveitar o benefício de se fazer perto, mesmo estando longe.

\section{PERCEPÇÕES ESTÉTICAS PARTILHADAS EM RODA}

Ao longo dos nossos encontros de coordenadores, compartilhamos as simbologias das flores e fomos convidados a estender essas percepções nas rodas locais. A roda São Gabriel foi desafiada a identificar uma flor que a representasse. Comumente utilizamos o girassol, símbolo das escolas do campo de onde grande parte do nosso grupo é atuante, mas o desafio foi além, foi olhar o belo ao nosso redor.

Nos deparamos com a flor do dente de leão (bem atípico, eu sei), Taraxacum officinale F.H. Wigg, de acordo com o relatado entre os colegas, esta planta simboliza a força, a esperança e a confiança. Pela sua característica de liberar as sementes ao vento, no processo de dispersão, essa planta representa a superação do medo ou o receio inicial, elas se deixam levar pelo fluxo da vida, curiosas sobre novas descobertas e prontas para criarem uma nova vida (NOGUEIRA, 2021, p. 2). Impossível não relacionar essa flor a nós professores, 
superando todos seus medos e enfrentando uma educação totalmente diferente da nossa zona de conforto, desbravando a tecnologia e sistemas até então desconhecidos. Ver figura 3.

Figura 3- Dispersão de sementes de Dente-de-leão

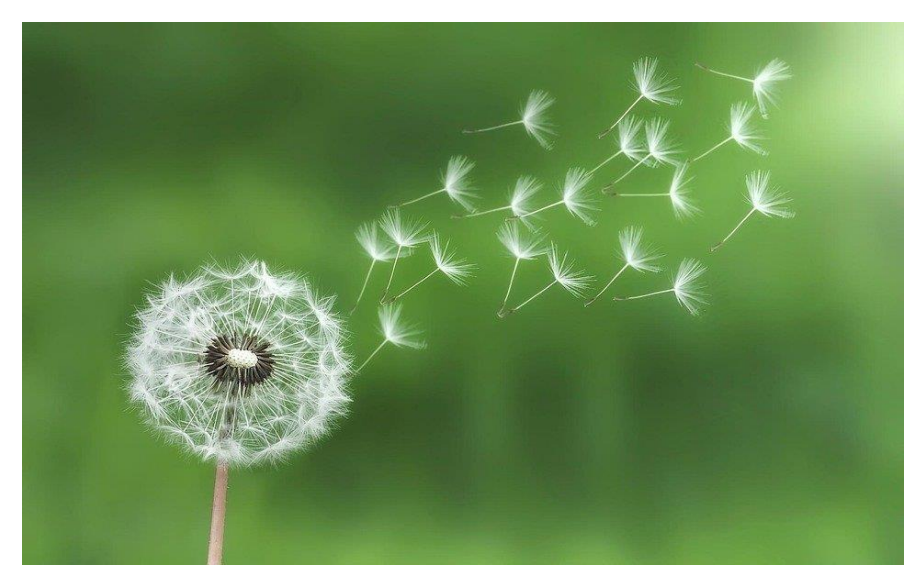

Fonte: Pixabay.com

Assim, fomos vivenciando em cada encontro, ali pela tela do computador, muitas emoções, choros, risadas, música, poesia e escuta atenta, a cada anseio e vivência relatada. Nossa roda composta desde gestores à acadêmicos, experientes ou estreantes na docência, ali estávamos em roda, distastes fisicamente, mas de mãos dadas para agarrar a oportunidade de vivenciar uma formação tão rica em significado e aprendizagens para nós professores. Vivenciávamos juntos um tempo de incertezas, buscando uma luz, um caminho, um apoio quanto as nossas tentativas, e percebemos juntos, em roda, que como diz a letra de uma música de Tiago Iorc (2019) que apreciamos em uma das nossas rodas, "nada como um dia após o outro".

\title{
Um dia após o outro
}

\author{
Tiago Iorc \\ Pra começar \\ Cada coisa em seu lugar \\ E nada como um dia após o outro \\ Por que apressar? \\ Se não sabe onde chegar \\ Correr em vão se o caminho é longo \\ Quem se soltar, da vida vai gostar \\ E a vida vai gostar de volta em dobro
}




\author{
E se tropeçar \\ Do chão não vai passar \\ Quem sete vezes cai, levanta oito \\ Quem julga saber \\ E esquece de aprender \\ Coitado de quem se interessa pouco \\ E quando chorar \\ Tristeza pra lavar \\ Num ombro cai metade do sufoco \\ O novo virá \\ Pra re-harmonizar \\ A terra, o ar, a água e o fogo \\ E sem se queixar \\ As peças vão voltar \\ Pra mesma caixa no final do jogo \\ Pode esperar \\ O tempo nos dirá \\ Que nada como um dia após o outro
}

$* * *$

\title{
A RODA FINAL
}

No mês de abril de 2021, em um sábado pela manhã, estávamos em roda, cada um de sua casa, realizando uma ciranda diferente mas riquíssima em afeto e partilha. Nesse novo formato on-line, o encontro final do Cirandar deixou-nos com saudade do café compartilhado e das conversas em roda, mas em contrapartida possibilitou o encontro e o reencontro de muitos colegas, amigos, docentes que partilham da vontade de estar em formação e principalmente, em autoformação.

Cada grupo foi convidado a expressar o seu olhar sobre o Cirandar edição de 2020. Nossa roda de São Gabriel, após encontros online e muita conversa através do grupo de WhatsApp optou por fazer um destaque à ciranda de todos os cantos, do quanto estávamos conseguindo estar juntos mesmo tão distantes. Com a dinâmica através de site Mentimeter, todos foram convidados a indicar seu município de origem e o município em que residem atualmente. Encontramos uma imagem com muitas cidades e estados entrelaçados, em movimento através da página do computador, fazendo uma ciranda com nossas trajetórias de vida. Ver figura 4: 
Figura 4- Ciranda de cidades elaborada no encontro

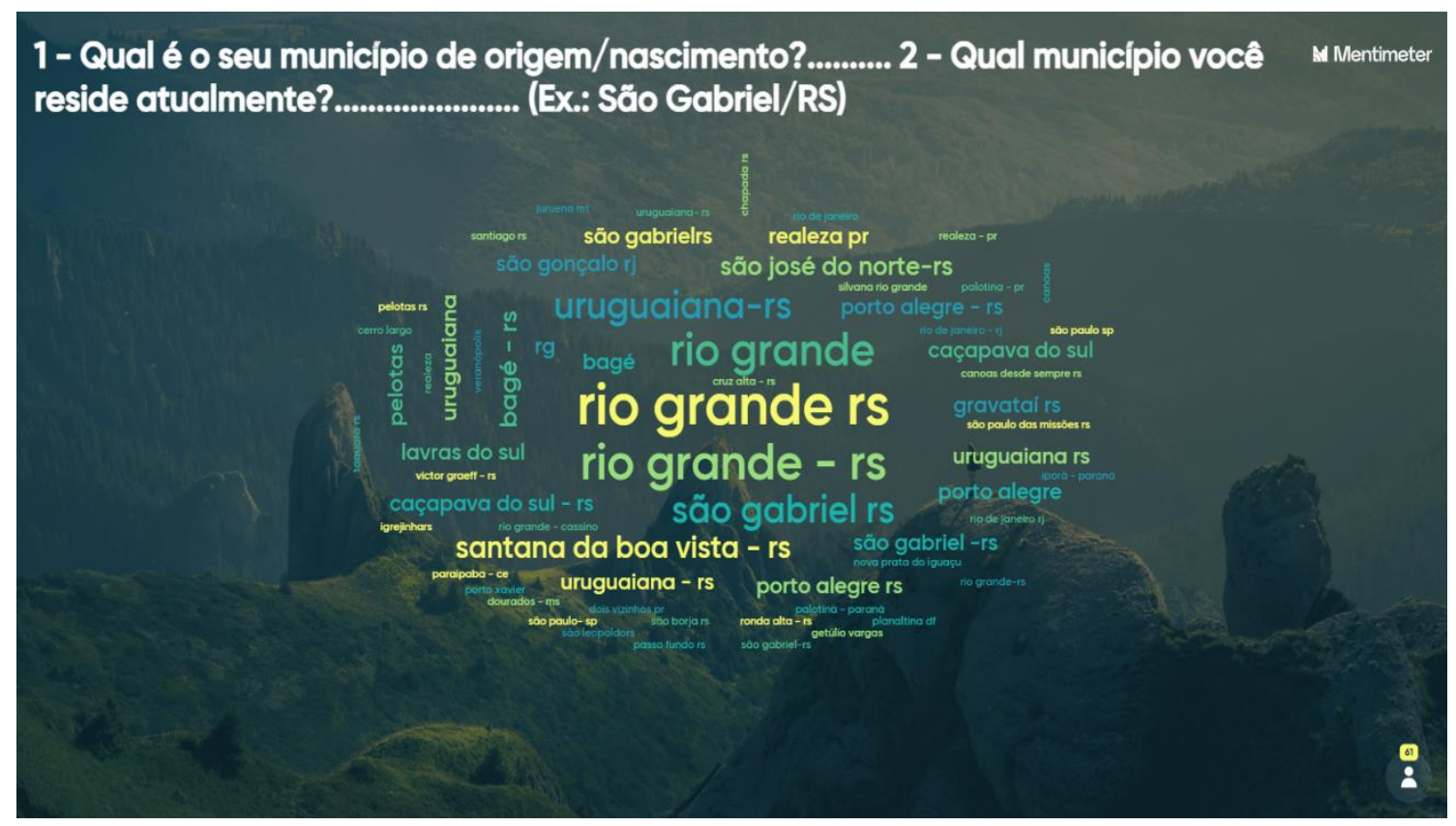

Fonte: menti.com

Vivenciando tempos difíceis como o atual, em que a educação encontra-se sendo ainda mais atacada frente a situação da pandemia, precisamos estar unirmos como docentes. Partilharmos nossas experiências, dúvidas e aprendizagens. $\mathrm{O}$ recurso tecnológico que era desconhecido para muitos, tornou-se ferramenta de trabalho, mas também de possibilidades. Isso que o Cirandar 2020 representou para nosso grupo, uma expressão de resiliência, acolhida, escuta atenta, aprendizagens e renovação.

A ciranda tem que continuar. Com o compartilhamento das cartas de todos os colegas também em formato digital, torna possível a cada vez que queremos sentirmos em roda, recorrer a leitura de uma carta, e logo já nos sentimos novamente de mãos dadas na ciranda.

$* * *$

\section{CARTA 3 - ENVIADA NA ETAPA FINAL DA FORMAÇÃO}

São Gabriel, 5 de janeiro de 2021.

\section{Olá colegas Cirandeiros}


Que gratificante a oportunidade de podermos compartilhar como foi viver nossa docência no ano de 2020, em meio ao enfrentamento de algo totalmente desconhecido para nós. Nesta carta pretendo contar sobre isso, as adaptações necessárias, as angustias vividas e também as conquistas realizadas nesse período. Mas para que vocês me entendam, vou primeiramente me apresentar e relatar brevemente meu contexto atual na docência.

Sou natural de São Gabriel-RS, nasci e cresci em meio aos planejamentos escolares e pelos corredores da escola que minha mãe trabalhava. Meus estudos de docência iniciaram na FURG, onde cheguei com 17 anos, distante $350 \mathrm{~km}$ de casa, com a certeza de que cursar licenciatura em Ciências Biológicas naquela universidade era fruto de muita batalha e percorri um longo caminho até estar como professora na educação básica, onde descobri ser o lugar em que me realizo.

As demandas da educação básica são diárias e assim surge o meu vínculo constante com a universidade, com grupos de professores em formação, com cursos de capacitações e/ou especializações que permitam momentos como esse de troca, de fala e principalmente de escuta. Diante dos desafios que fui encontrando na minha prática docente, fui guiando minha formação continuada, em um primeiro momento em educação especial e inclusiva, logo mais com a segunda licenciatura em Pedagogia e, na mescla de professora e estudante, fui me reinventando no meu fazer pedagógico.

E aqui estou, como fruto de toda essa caminhada que ainda se constitui no cotidiano, como professora em duas escolas do campo com realidades bem distintas, em uma delas como professora de Ciências do $6^{\circ}$ ano $9^{\circ}$ ano e na outra como professora do Atendimento Educacional Especializado.

Com a pandemia, nossos saberes sobre docência foram reavaliados. Em março, acompanhando a evolução da pandemia com a sensação de ver uma tsunami se aproximando, nos deparamos com a necessidade geral de parada, sendo ela decretada aqui na cidade de São Gabriel no dia 16 de março, com o prazo de dois dias para "organizarmos" essa parada e deixarmos atividades para os alunos realizarem em casa. Saí da escola para retornar em 15 dias. Desestruturada como docente, no sentido de que essa era uma situação tão inédita que não tinha onde procurar orientações de como fazer. 
Em poucos dias já sabíamos que não seria só uma quinzena de pausa. Foi necessário adaptar as atividades a serem enviadas pois a rede municipal se organizou para realizar a entrega do material aos alunos pelo acesso restrito a internet nas comunidades do campo. Esses alunos passaram a receber quinzenalmente o material via transporte escolar, alguns enviavam fotos das atividades via WhatsApp, alguns enviavam o material na quinzena seguinte para correção e de outros não tivemos retornos.

Começaram os atendimentos aos alunos de madrugada (pois a internet no campo parece funcionar melhor nesse horário) e aos finais de semana sem dia e horários definidos, trabalhando praticamente $20 \mathrm{~h}$ por dia. Mescla de tarefas domésticas com ansiedade da pandemia, com material a ser elaborado e a ser respondido aos alunos e a angustia de que algo não estava dando certo, que não estava conseguindo contato com $100 \%$ dos alunos e uma overdose de rede social com lives e reuniões pedagógicas na esperança de encontrar um suporte para tudo aquilo... até o sentimento de basta, não dá mais. E assim começou a segunda etapa da minha adaptação com a docência e pandemia.

Comecei a organizar melhor os dias e horários de trabalho para cada escola. Identifico que o principal momento de organização foi estabelecer metas, entre elas que apesar de ser o ano organizado para seguir a BNCC, nesse momento não tinha como focar em lista de objetos do conhecimento. Decidi dar prioridade ao contato com os alunos e atividades vinculadas ao cotidiano. Logo percebi o quão pouco sabia dos alunos, se estavam conseguindo se cuidar, se estavam bem dentro do contexto social e emocional. Muitas mensagens, cartas e áudios foram trocados nesse sentido, na percepção de que para eles, alunos do campo, a ausência da ida até a escola era muito maior do que a perda do conteúdo. Eles estavam perdendo vivencias que só o tempo vai permitir recuperar.

A partir daí, cada material impresso que enviei, passou a ter mais do que apenas conteúdo. Cada material começa com um avatar e um recadinho, uma frase de incentivo ou uma pergunta para ser retornada. No intuito de dar a sensação de que estava ali com eles conversando e não apenas um texto com conteúdo. Passei a estimular as atividades chamadas "roda de conversa", onde enviava uma reportagem curta e convidava o aluno a ler em família e coletar com eles as respostas para algumas perguntas, com o objetivo de inserir a família na atividade mas principalmente de estimular o diálogo. 
As famílias que participaram deram contribuições incríveis e possibilitaram aos alunos perceberem que a "Ciência" está além do livro didático, conversando sobre alimentação, depressão, abuso de bebida alcoólica, impactos ambientais, vacinação, extinção de espécies nativas, entre outros.

Ao longo desse período de adaptação da docência, me deparei com diversos relatos e vídeos de que a pandemia valorizou o professor e a educação. Vejo aqui um dos temas que precisam ser discutidos e descritos sobre a educação durante a pandemia. Afinal, qual é o papel da escola? Qual é o papel que as famílias atribuem à escola?

Por todo período em que atuo como docente vejo constantes buscas de aproximação família e escola, com aquela percepção da prática de que as famílias dos alunos que mais precisam de atenção estão ausentes do ambiente escolar. Mas era uma percepção do tipo “de corredor", sem nenhum cunho de pesquisa e ou análise mais profunda, porque no cotidiano escolar resta pouco tempo para analises mais profundas entre tantas demandas.

A pandemia nos fez parar e planejar alternativas, exigiu essas análises mais profundas e isso escancarou algumas situações já presentes mas não tão destacadas: existem famílias que são contra as escolas, que apenas cumprem a obrigação e, além de não apoiarem, elas desenvolvem ações contrárias, como manifestações perante as crianças e nas redes sociais, desqualificando o sistema de ensino e desvalorizando o que é desenvolvido em um ambiente escolar.

Não é meu objetivo discutir nessa carta o papel da educação básica, tema recorrente em trabalhos acadêmicos e de consagrados estudiosos da área. Meu objetivo é descrever algumas percepções que ficaram mais claras nesse período escolar em meio a uma pandemia, em que alguns conceitos foram exemplificados, como os de Libâneo (2010, p.13) descrito em um dos seus textos intitulado "escola de conhecimento para ricos e de acolhimento social para pobres", e outros autores como Nóvoa (2009, p.79) que discorre sobre os objetivos assistencialistas, aos quais ele denomina como "transbordamento da escola" se sobreporem aos objetivos de aprendizagem. A releitura de alguns textos base sobre educação parecem ganhar novo peso com a experiência atual que a educação básica está vivenciando. Estes questionamentos estão aflorados, mas meu pensar nesse momento vai além do que nós educadores pensamos ser o papel da escola, 
uso essa carta para refletir o que as famílias demostraram acreditar ser o papel da escola???

Alunos se distanciaram da escola com o fato de não ser obrigatório. A falta de informação sobre métodos de avaliação e retenção ou não retenção fez escancarar a percepção de que só buscam o "passar o ano" sem sequer avaliarem o que isso significa. Os professores foram submetidos a famosa "busca ativa", em que se colocaram no papel de solicitar favor ao aluno de que dessem ao menos algum retorno. Não cabe aqui fazer a lista de problemas que encontramos como a falta de acesso à tecnologia, estou me referindo aos que abandonaram de livre e espontânea vontade com total aval familiar, desqualificando tudo o que foi realizado nesse período como desnecessário, já que todos iriam passar de ano.

Mais algum colega professor se sentiu incomodado com isso como eu me senti? Mais alguém sentiu que não era uma questão de repetência ou não, não era uma questão de conteúdo, não era uma questão de hierarquia, que foi uma questão de respeito? Que nos colocamos em um papel de cumprindo obrigação enquanto os alunos/famílias nos prestavam um favor? Mais algum colega professor foi bloqueado por aluno e/ou teve todas as suas mensagens visualizadas e não respondidas? Mais algum colega professor se questionou se "aprovar" um aluno que realizou poucos retornos de atividades pode não ter sido positivo para esse aluno? Mais algum colega professor acredita que o objetos do conhecimento não desenvolvido esse ano se recupera mas que o respeito pela escola talvez não?

Como citei antes nessa carta, não era meu objetivo realizar uma análise do papel da escola, conteudista e/ou social e assistencialista, era expor percepções que se tornaram evidentes nesse ano letivo atípico.

Precisamos de espaços para discutirmos isso que não sejam apenas post de piadas nas redes sociais, pois foram o que mais surgiram, cumprindo a expressão popular "rindo para não chorar".

Mas para não finalizar essa carta apenas com as incertezas e os problemas, relato também o que teve de positivo em 2020 com a pandemia. Fronteiras foram ultrapassadas no sentido de formação. Professores que buscam participar de cursos e eventos, tiveram a possibilidade nesse ano de acompanhar eventos maravilhosos. Participei de formações 
e eventos que se fossem presenciais meu orçamente, tempo de deslocamento e liberação na escola não possibilitariam participar.

Encontrei em alguns alunos e famílias aquela frase, aquele retorno que compensavam todos os outros não ocorridos. Tive tempo de tomar café da tarde com a família no intervalo das atividades já que não era necessário as 4 horas de deslocamento entre ida e volta até a escola do campo, pude ler e reler livros que estavam a anos na minha estante e a rotina semanal não estavam me permitindo ler.

Minha docência na pandemia teve uma certeza entre tantas dúvidas, a de que eu fiz o meu melhor, não apenas o possível. Busquei a cada dia passar aos meus alunos a confiança de que íamos superar esse período e que conteúdo não era o mais importante no momento. Busquei despertar em cada um deles o interesse e a curiosidade em aprender nas situações que são possíveis, muito além do que as paredes da sala de aula. Certamente não obtive sucesso com todos.

Chego nessa etapa do ciclo de pandemia cansada, ainda angustiada com a falta de perspectivas de como será esse retorno e com a falta de incentivo e planejamento sobre a vacinação em nosso país. Vejo outras tantas necessidades a serem ajustadas na educação que a pandemia salientou. Mas sigo um dia de cada vez, permitindo novo olhar até mesmo para o período de recesso escolar, como um período de reestruturação além do descanso, inspirada em uma frase de Carpinejar (2020, p.117) "há hora para navegar e hora para reparar o barco, nem tudo na vida é alto-mar”, após um ano letivo tão desafiador, mais do que nunca precisamos de um período de reparação para logo estarmos prontos a navegar.

Um abraço a cada colega professor que navegou nas turbulências do ano letivo de 2020.

Loraine Rodrigues Jardim

$$
* * *
$$

\section{CONCLUSÃO}

A ciranda precisa estar em movimento. Cirandamos de mãos dadas, guiando e sendo guiados, apreciando o momento e aprendendo com ele. Assim foi nosso Cirandar edição de 2020, um momento em que nos demos as mãos, que nos mantivemos em 
movimento, que guiamos e fomos guiados em busca de aprender e reaprender a fazer nossa docência em uma situação ainda não vivenciada por nenhum de nós. A pandemia escancarou os problemas da educação básica, colocou ainda mais os holofotes das críticas nos professores. Exigiu que, quem ainda não conhecia tecnologia, a vivenciasse em todos os momentos do dia. Através dessa tecnologia, desse online, encontramos nossos alunos, fomos docentes e discentes, choramos e sorrimos, estivemos distantes e ao mesmo tempo juntos, de mãos dadas. Cirandamos em busca de apoio, de escuta, de movimento e seguiremos firmes nessa roda, juntos, nos formando em cada roda, em cada partilha, pois quem conhece o Cirandar aprende também a querer mais. Vida longa ao Cirandar!

\section{REFERÊNCIAS}

BETTIOL, M.R.B. Mário de Andrade e a especificidade do gênero epistolar: o esboço de uma teoria. Revista do instituto de Estudos Brasileiros. N65. Dez 2016 (p.227-236) Disponível em: 〈https://www.scielo.br/pdf/rieb/n65/2316-901X-rieb-65-00227.pdf> Acesso em: 20 de abr. 2021.

CARPINEJAR, F. Colo, por favor: Reflexões em tempo de isolamento. São Paulo: Planeta, 2020.

IBGE. IBGE Cidades. Brasília: IBGE, 2021. Disponível em: 〈https://cidades.ibge.gov. br/brasil/rs/sao-gabriel/panorama>. Acesso em: 04 de mai. 2021.

IORC, T. Música Um dia após o outro. (2019) Disponível em: < https://www.letras.com. br/tiago-iorc/um-dia-apos-o-outro> Acesso em: 06 de out. 2020.

LIBÂNEO, J.C. O dualismo perverso da escola pública brasileira: escola do conhecimento para os ricos, escola do acolhimento social para os pobres. Educação e Pesquisa, São Paulo, v. 38, n. 1, p. 13-28, 2012. Disponível em: 〈https://www.scielo.br/pdf/ep/v38n1/aop323.pdf.> Acesso em: 20 de nov. 2020.

MENTIMETER. Disponível em: 〈https://www.menti.com/> Acesso em: 24 de abr. 2021. NOGUEIRA, L. Sabedoria divina da natureza- Ep 34 - Dente-de-lesão. 2018. Disponível em: 〈https://encontrocomanatureza.blogspot.com/2018/05/sabedoria-divinada-natureza-ep-34.html> Acesso em: 16 de out. 2020. 
NÓVOA, A. Professores: imagens do futuro presente. Lisboa: Educa, 2009. Disponível em: <https://rosaurasoligo.files.wordpress.com/2017/04/antc3b3nionc3b3voa-professores-imagens-do-futuro-presente.pdf.> Acesso em: 20 de nov. 2020.

PASTORIO, E. Nucleação das Escolas do Campo: o caso do município de São Gabriel/RS. 2015. 162 f. Dissertação (Mestrado em Geografia) - Programa de PósGraduação em Geografia, Universidade Federal de Santa Maria, Santa Maria, 2015.

PIXABAY. Imagem dente-de-lesão. Disponível em: <https://pixabay.com/pt/photos/ dente-de-le\%C3\%A3o-facilidade-v\%C3\%B4o-2338138/> Acesso em: 20 de abr. 2021.

Recebido em: 17 de maio de 2021. Aceito em: 19 de maio de 2021. 